\title{
ACTUALIDAD LEGISLATIVA
}

\section{Jaime Alcalde Silva}

Profesor asociado de Derecho Privado

Pontificia Universidad Católica de Chile

INFORMe SOBRe EL Derecho COOPERATIVO CHILENO ${ }^{1}$

\section{INTRODUCCIÓN}

La experiencia cooperativa en Chile se remonta a 1887, cuando un grupo de artesanos del puerto de Valparaíso fundó la primera empresa inspirada en un ideal de utilidad común y ayuda mutua que emulaba a los pioneros de Rochdale. Sin embargo, habría que esperar hasta 1924 para que se promulgase una ley específica para este tipo de empresas (ley $\mathrm{N}^{\mathrm{O}} 4058$ ) como consecuencia de la adopción de un conjunto de medidas destinadas a enfrentar la cada vez más acuciante "cuestión social". Mientras tanto, las cooperativas que se crearon hubieron de adoptar alguna de las formas societarias existentes en el Derecho Civil o Comercial, con las correcciones estatutarias propias de su carácter.

Según los datos oficiales del Ministerio de Economía, Fomento y Turismo, en la actualidad ( 15 de agosto de 2013) existen en el país 4937 coopera-

\footnotetext{
${ }^{1}$ Este informe es parte del proyecto AnilloCONICYT de investigación asociativa, código SOC 1111. En él se desarrolla la versión española del capítulo sobre Derecho chileno que se puede consultar en CRACOGNA, FicI, HenRŸ (eds.) (2014).
}

tivas, las que cuentan con 1.920.044 socios. De ellas, 1061 se encuentran vigentes y operativas y 1664 tienen su sede en la Región Metropolitana. En términos financieros, estas empresas presentan un consolidado de activos que alcanza los USD\$4.632.000.000, con un patrimonio levemente superior a USD\$2.000.000.000, ingresos operacionales de casi USD $\$ 1.500 .000 .000$ cada año y unas utilidades en igual período ascendentes a USD\$115.000.000. Así, pues, y pese a que comparativamente su aporte a la economía nacional es menor que otras formas asociativas, destaca su contribución en el ámbito de los servicios financieros, la producción agrícola, el acceso a la vivienda, el suministro de agua potable y la electrificación rural.

El presente informe tiene como propósito mostrar un panorama general del Derecho Cooperativo chileno que pueda ser útil para cualquiera que desee formarse una primera impresión sobre el particular. No hay en él más que un ánimo informativo o descriptivo, sin mayor pretensión dogmática que la de dar algunas pinceladas que delineen las instituciones, reglas y principios que componen la regulación normativa que existe en Chile sobre las cooperativas, de manera que versados y profanos 
puedan acercarse a ella sabiendo al menos el derrotero de su trazado. Esta finalidad explica que se haya decidido prescindir de un sistema de notas, para ofrecer un texto compuesto con el deseo de alcanzar una mayor claridad y simpleza en el relato. En compensación se ofrece al final una orientación bibliográfica, que permitirá al lector interesado conocer en su contexto lo que se ha publicado sobre el tema y profundizar en algún aspecto que sea de su especial interés.

\section{LAS FUENTES \\ del Derecho Cooperativo chileno}

A diferencia de otros ordenamientos, en la Constitución Política de la República no existe una referencia expresa a las cooperativas como forma de organización económica digna de promoción por parte del Estado. Pese a tal omisión, ella contempla una serie de normas que, directa o indirectamente, fundamentan o son aplicables al movimiento cooperativo, entre las que cabe destacar el principio de subsidiariedad ( $\left.\operatorname{art} .1^{\circ} \mathrm{III}\right)$; el carácter servicial que se asigna al Estado y su ordenación al bien común (art. $1^{\circ} \mathrm{IV}$ ); el derecho de asociación (art. 19 $\mathrm{N}^{\mathrm{o}} 15$ ); el derecho de desarrollar cualquier actividad económica que no sea contraria a la moral, el orden público o la seguridad nacional, con sujeción a las normas que la regulen (art. $19 \mathrm{~N}^{\mathrm{o}}$ 21) y el derecho de propiedad en sus diversas especies, sobre toda clase de bienes corporales e incorporales (art. 19 $\left.\mathrm{N}^{\mathrm{o}} 24\right)$.

De ahí que el Derecho Cooperativo chileno sea eminentemente de origen legal y reglamentario. El texto definitivo de la actual LGC fue sancionado por el DFL 5/2003, dictado en cumplimiento de la habilitación contenida en la ley $\mathrm{N}^{\mathrm{O}} 19.832$, cuyas disposiciones vienen complementadas por un reglamento aprobado merced al DS 101/2004, del Ministerio de Economía, Fomento y Turismo (RLGC). Pese a su data reciente, estos cuerpos normativos no se encuentran en afinidad con la última definición del ideario propuesto por la Alianza Cooperativa Internacional y recogido en la Declaración sobre Identidad Cooperativa (1995), dado que la mentada ley $\mathrm{N}^{\mathrm{o}} 19.832$ tardó once años en ser sancionada desde que su proyecto fuera presentado al Congreso Nacional por el presidentePatricio Aylwin(Mensaje de 11 de noviembre de 1992, Boletín $\mathrm{N}^{\circ} 855-03$ ). También es anterior a la revisión de la LMCAL, sancionada por el Consejo Consultivo de ACI-Américas celebrado en julio de 2008, y a la recomendación No 193/2002 de la OIT sobre promoción de las cooperativas por parte de los Estados.

Fuera del citado reglamento, como fuentes del Derecho Cooperativo comparecen también

i) algunos decretos relevantes emanados de la potestad reglamentaria de la Subsecretaría de Economía del Ministerio de Economía, Fomento y Turismo (art. $32 \mathrm{~N}^{\circ} 6^{\circ}$ de la CPR);

ii) las resoluciones dictadas por el Departamento de Cooperativas, dependiente de esta misma subsecretaria, con el propósito de perfeccionar el funcionamiento de las cooperativas (art. 108 
de la LGC) en las distintas facetas de su actividad empresarial (art. 109 de la LGC) y

iii) aquellas circulares y resoluciones provenientes de otros organismos públicos con competencias de supervisión sobre el actuar de las cooperativas (por ejemplo, la Superintendencia de Bancos e Instituciones Financieras o el Servicio de Impuestos Internos).

\section{DEFINICIÓN Y PROPÓSITO DE LAS COOPERATIVAS}

Las cooperativas son:

"asociaciones que de conformidad con el principio de la ayuda mutua tienen por objeto mejorar las condiciones de vida de sus socios [...]" (art. $1^{\circ}$ de la LGC)

mediante el desarrollo de las actividades que les son propias (art. $2^{\circ}$ de la LGC). Quizá el rasgo más importante de esta definición sea el cuidado que se ha puesto en evitar incluir las cooperativas dentro del género de las sociedades, como lo hacía el art. $1^{\circ}$ de la ley $\mathrm{N}^{\circ} 4.058$. Se reafirma así el carácter específico de esta figura asociativa, diferenciado de las sociedades en sentido estricto y centrado en la idea de colaboración recíproca y solidaridad.

El concepto técnico que permite comprender el régimen jurídico de la sociedad y sus conflictos de interés específicos es el ánimo de lucro con que se unen los socios. No basta con que una sociedad aspire a ahorrar o hacer economías de escala, ya que toda empresa es una organización de capital y trabajo concebida para la maximización de resultados; para que haya lucro, es necesario que se persiga la obtención de un incremento del patrimonio social ilimitado repartible entre los socios en el corto o largo plazo (máxima de la economicidad). Ese ánimo de lucro existe por igual en las sociedades civiles y comerciales, porque unas y otras se caracterizan igualmente por la puesta en común de ciertos bienes y servicios con miras a repartir entre los socios los beneficios que de ello provengan (art. $2053 \mathrm{del}$ $C C$ ), diferenciándose fundamentalmente en el objeto de su giro y en la responsabilidad de aquéllos respecto de las deudas sociales. Tal afán no existe en las cooperativas y, por esa razón, ellas son consideradas asociaciones sin fines de lucro (art. 53 de la LGC) enderezadas a mejorar las condiciones de vida de sus socios, en algún aspecto particular, a partir de un principio de ayuda mutua (art. $1^{\circ}$ de la LGC), el que se concreta a través de las actividades que la entidad se propone sacar adelante según el giro que les es propio (arts. $2^{\circ}$ y $6^{\circ}$ b) de la LGC y 2 a) del RLGC). Esta ausencia de ánimo de lucro explica, por ejemplo, que se entienda que las cooperativas no producen utilidades, salvo para el cálculo de las gratificaciones que se han de pagar a los trabajadores de acuerdo con los arts. 46-52 del $C T$ (art. 53 de la LGC), o que las cooperativas de consumo no puedan operar mediante el giro o emisión de órdenes de compra a favor de sus socios y en interés del comercio privado (art. 92 de la LGC). 
En afinidad con el principio constitucional que garantiza el libre ejercicio de cualquier actividad económica (art. $19 \mathrm{~N}^{\mathrm{o}} 21$ de la CPR), las cooperativas pueden tener por objetivo cualquier actividad lícita (arts. $1445 \mathrm{~N}^{\circ} 3^{\circ}$ de $C C$ y $2^{\circ}$ de la LGC), y aun combinar varias de ellas (art. $3^{\circ}$ de la LGC), con la única limitación de que no pueden dedicar su actividad a otros objetos distintos a los señalados específicamente en los estatutos [art. 2 a) del RLGC]. A diferencia de otras legislaciones hispanoamericanas, la ley chilena no hace mención al concepto de "acto corporativo" para delinear el campo de acción de estas entidades, y que cabe definir como todo aquél realizado entre las cooperativas y sus socios o por las cooperativas entre sí en cumplimiento de su objetivo social y sometido al Derecho Cooperativo (art. $7^{\circ}$ de la LMCAL). Basta, en suma, que la actividad de una cooperativa se realice mediante cualquier acto que sea idóneo para el cumplimiento de su objeto, sin importar que la persona con quien se interactúa sea un socio, un tercero, otra cooperativa, una sociedad de cualquier clase o, incluso, el mismo Estado. Esto trae consigo que las cooperativas queden sujetas por igual a su régimen jurídico propio (LGC y RLGC) y a las leyes especiales que rigen la actividad económica que constituye su objeto (art. $2^{\circ}$ iI de la LGC).

\section{IV. Ámbitos DE LA ACTIVIDAD COOPERATIVA}

1) La actividad económica que desarrolla una cooperativa no se dirige sólo a los socios que la componen,

2) ya que la ley admite expresamente que éstas puedan operar con terceros.

\section{La actividad de la cooperativa con sus socios}

Las cooperativas pueden tener por objetivo cualquier actividad enderezada a mejorar las condiciones de vida de sus socios (arts. $1^{\circ}$ y $2^{\circ}$ de la LGC), propósito que cumplen mediante el desarrollo de sus fines específicos [arts. $3^{\circ}$ y $6^{\circ} \mathrm{b}$ ) de la LGC y 2 a) del RLGC]. Según la actividad que realizan, el ordenamiento establece algunas normas especiales para la constitución y funcionamiento de ciertas cooperativas. Distingue así entre cooperativas de trabajo (art. 6064 de la LGC), agrícolas y campesinas (art. 65 y 66 de la LGC), pesqueras (art. 67 de la LGC), de servicio (arts. 68-90 de la LGC y 141-160 del RLGC) y de consumo (arts. 91-93 de la LGC). Adicionalmente, es posible constituir dos clases de cooperativas especiales: las especiales agrícolas y las especiales de abastecimiento de energía eléctrica (arts. 94-100 de la LGC). A ellas les son aplicables las disposiciones comunes por las que se rigen las cooperativas agrícolas (arts. 65 y 66 de la LGC) y las de abastecimiento de energía eléctrica (arts. 72 de la LGC y 161 del RLGC), además de las normas particulares del título $\mathrm{V}$ de la LGC, que priman sobre aquéllas cuando unas y otras resulten incompatibles entre sí. Entre esas peculiaridades conviene mencionar su régimen tributario (art. 100 de la LGC) y el sistema de voto ponderado (art. 99 de la LGC). 
Con todo, cumple advertir que las cooperativas pueden combinar finalidades de diversas clases, salvo las que deban tener objeto único, como las cooperativas abiertas de vivienda, las de ahorro y crédito y cualquier otra que establezca la ley $\left(\operatorname{art} .3^{\circ} \mathrm{de}\right.$ la LGC). El objeto social debe estar descrito en los estatutos y no se admite que una cooperativa aboque su actividad a objetos diversos a los ahí mencionados [arts. $6^{\circ} \mathrm{b}$ )de la LGC y 2 a) del RLGC].

\section{La actividad de la cooperativa con terceros}

La ley extiende la actividad cooperativa a terceros [arts. $4^{\circ}, 60,86$ a) y p) de la LGC] e, incluso, permite que la entidad constituya garantías reales o personales a su favor [art. 23 h) y n) de la LGC]. Sin embargo, dada las particularidades que conforman su régimen, es necesario evitar que esas operaciones se celebren en fraude de ley (art. 11 del $C G$ ). De ahí que se prohíba que con ocasión de esos negocios la cooperativa establezca con terceros combinaciones o acuerdos que hagan participar a éstos directa o indirectamente de los beneficios tributarios o de otro orden que la ley otorga a estas entidades (art. $4^{\circ}$ de la LGC). La distinción entre las operaciones que la cooperativa realiza con sus socios y con terceros tiene importancia para determinar el destino de los excedentes, pues los provenientes de la primera clase se repartirán a prorrata de las mismas operaciones, mientras que los de la segunda clase se distribuirán en proporción a las cuotas de participación (art. 38 II de la LGC), así como la carga tributaria que eventualmente los grabará (art. 52 de la LGC).
Los terceros merecen, asimismo, una protección especial cuando la cooperativa sólo tiene una existencia de hecho por no haber cumplido las formalidades previstas para su constitución. Cuando eso ocurre, la cooperativa da origen a una comunidad entre los socios que han concurrido a su formación (art. 10 II de la LGC), quedando éstos obligados solidariamente hacia los terceros con quienes hubiesen contratado a nombre e interés de aquélla (art. 10 III de la LGC). Algo similar ocurre cuando la cooperativa se ha disuelto por el vencimiento del plazo de duración o por alguna de las causas señaladas en los estatutos [art. 43 a) y c) de la LGC]. Si han transcurrido más de sesenta días desde el acaecimiento de uno de estos eventos sin que el consejo de administración consigne el hecho por escritura pública, inscriba su extracto en el Registro de Comercio y lo publique en el Diario Oficial, cualquier tercero interesado podrá dar cumplimiento a tales formalidades (art. 44 de la LGC).

\section{REQUisitos y FORMALIDADES DE CONSTITUCIÓN}

El proceso de creación de una cooperativa comienza por la celebración de una junta general constitutiva, cuya acta debe ser reducida a escritura pública y expresar el nombre, profesión o actividad, domicilio y cédula nacional de identidad de los socios que concurren a su constitución (arts. $6^{\circ}$ de la LGCy $1^{\circ}$ y $3^{\circ} \mathrm{del} \mathrm{RLGC)}$. La regla en esta materia es que las cooperativas se constituyen con el número de socios que deseen participar en ellas, que no puede ser inferior a diez (art. 13 de la LGC), salvo 
en el caso de las cooperativas de trabajo (art. 60 de la LGC), de ahorro y crédito (art. 88 de la LGC), de consumo (art. 91 de la LGC) y abiertas de vivienda (art. 84 de la LGC), en que el número mínimo de es de cinco, cincuenta, cien y trescientos socios, respectivamente. En dicha acta deberá constar también la aprobación de los estatutos y el texto íntegro de éstos, de cuyo contenido mínimo tratan los arts. $6^{\circ}$ de la LGC y $2^{\circ}$ del RLGC. Un extracto de la escritura social, autorizado por el notario respectivo, deberá inscribirse en el Registro de Comercio correspondiente al domicilio de la cooperativa, y publicarse por una sola vez en el Diario Oficial (art. $7^{\circ}$ I y II de la LGC). El plazo para efectuar esta inscripción y publicación es de sesenta días y se cuenta desde la reducción a escritura pública de la mentada acta (art. $7^{\circ}$ III de la LGC). Sólo cuando se han cumplido todos estos trámites, la cooperativa puede iniciar sus actividades y realizar las operaciones propias de su giro (art. $6^{\circ}$ del RLGC).

La cooperativa constituida de acuerdo con los trámites exigidos por la ley posee personalidad jurídica (art. $5^{\circ}$ de la LGC) y sigue gozando de ella, incluso, después de su disolución para los efectos de su liquidación (art. 48 de la LGC). En ciertos supuestos se admite que la cooperativa respecto de la cual no se hayan observado todos los requisitos que le son propios pueda ser saneada según el procedimiento de la ley $\mathrm{N}^{\mathrm{O}}$ 19.499 (arts. $9^{\circ}$ y 11 de la LGC); pero no podrá serlo si ella no consta en escritura pública o en instrumento reducido a escritura pública, o cuyo extracto no se haya inscrito o publicado. Si así ocurre, sólo se reputará existir una comunidad entre sus miembros, y las ganancias y pérdidas se repartirán y soportarán y la restitución de los aportes se efectuará entre ellos con arreglo a lo pactado o a la disciplina supletoria prevista por la ley (arts. 10 de la LGC y $5^{\circ}$ del RLGC). Excepcionalmente, en las cooperativas de ahorro y crédito y en las abiertas de vivienda es necesario que los interesados en su constitución sometan al Departamento de Cooperativas un estudio socioeconómico sobre las condiciones, posibilidades financieras y planes de trabajo que se proponen desarrollar, de suerte que la junta general constitutiva sólo podrá celebrarse con posterioridad a la aprobación de dicho estudio (arts. 12 de la LGC y $7^{\circ}$ de la RLGC).

$\mathrm{Al}$ igual que sucede hoy con todas las sociedades, no existe ningún impedimento para que una cooperativa extranjera se pueda establecer y ejercer su actividad económica en Chile. Para hacerlo debe constituir una agencia que opere en el territorio nacional de conformidad a las normas de la ley $\mathrm{N}^{\mathrm{O}}$ 18.046 sobre sociedades anónimas (cfr. arts. 447-450 del CCom), la que queda sujeta a las normas de la Ley General de Cooperativas en lo que sea pertinente, pero no goza de los beneficios tributarios que la ley chilena reconoce a estas últimas (art. 122 de la LGC).

\section{El estatus DE SOcio}

El principio general es que pueden ser socios de una cooperativa tanto las personas naturales como las personas jurídicas de Derecho Público y Privado (art. 14 de la LGC). La adquisición, el ejercicio y la pérdida de la calidad de socio y las prestaciones mutuas a que 
haya lugar por estas causas, se regirán por los estatutos que la propia cooperativa se haya dado conforme a las normas legales vigentes (arts. 15 de la LGC y 11 del RLGC). A estos efectos, el reglamento de cooperativas es supletorio de las disposiciones estatutarias y sólo se aplica en silencio de las mismas. El único resguardo es que tales restricciones no pueden estar fundadas en razones de discriminación sexual, social, racial, política o religiosa (arts. $1^{\circ}$ y 16 de la LGC).

La calidad de socio se adquiere por cualquiera de las siguientes formas:

i) por la suscripción del acta de la junta general constitutiva en calidad de socio fundador;

ii) por solicitud aprobada por el consejo de administración, seguida de la adquisición a cualquier título de cuotas de participación, de conformidad con lo dispuesto en los estatutos;

iii) por sucesión por causa de muerte, cuando los estatutos autorizan que los herederos del socio fallecido continúen en la cooperativa formando una comunidad indivisa, que deberá ser representada por un procurador común (art. 13 del RLGC). De estas situaciones merece especial atención la segunda de ellas.

Para poder solicitar la adhesión a una cooperativa, el socio debe cumplir con dos condiciones mínimas:

i) capacidad para utilizar los servicios de la cooperativa y

ii) disposición a aceptar las obligaciones y responsabilidades inherentes a la condición de tal.

La primera condición viene determinada por el tipo de cooperativa de que se trata. Esto significa que cualquier persona, natural o jurídica, puede ser socio de una cooperativa en la medida que case con su objeto. Hay, empero, algunos límites:

i) ningún socio puede ser propietario de más de un 20\% del capital, salvo en el caso de las cooperativas de ahorro y crédito, en las que el máximo permitido es de un 10\% (art. 17 de la LGC), y en las cooperativas especiales agrícolas y de abastecimiento de energía eléctrica, en las que un socio puede tener un porcentaje máximo de capital de hasta un 30\% (art. 95 de la LGC);

ii queda excluida la creación de cuotas de participación de organización y privilegiadas (art. 33 de la LGC);

iii) los estatutos pueden prohibir que los trabajadores de la cooperativa adquieran en ella la calidad de socios, salvo que se trate de una cooperativa de trabajo (art. 27 del RLGC);

iv) en ciertos casos, para constituir una cooperativa es necesario contar con el número mínimo de socios requerido por la ley, que es en general de diez (art. 13 de la LGC).

Este primer requisito tiene como contrapartida la efectiva posibilidad de la cooperativa de contribuir al mejoramiento de las condiciones de vida de quien desea convertirse en socio mediante la particular actividad económica que desarrolla (arts. $1^{\circ}$ y $2^{\circ}$ de la LGC). De esta manera, las cooperativas pueden suspender transitoriamente el 
ingreso de socios cuando sus recursos sean insuficientes para atenderlos (art. 16 LGC).

La segunda condición para convertirse en socio de una cooperativa es estar dispuesto a aceptar las obligaciones y responsabilidades inherentes a ese estatus, las que son en principio iguales para todos (art. $1^{\circ}$ de la LGC). Estas obligaciones y responsabilidades deben estar indicadas en los estatutos, por lo que la ley y su reglamento se aplican sólo supletoriamente y en silencio de las disposiciones estatutarias (arts. $15 \mathrm{de}$ la LGC y 11 y 17 del RLGC).

Entre las obligaciones y responsabilidades que tiene el socio de una cooperativa merecen destacarse las siguientes:

i) el cumplimiento fiel de los estatutos (arts. $1545 \operatorname{del} C G ; 2^{\circ}$ y $6^{\circ}$ de la LGC y 1 y 2 del RLGC), de los reglamentos internos de la cooperativa (arts. 63, $64 \mathrm{y}$ 90 de la LGC y 2 del RLGC) y de los acuerdos adoptados por la junta general [arts. 21 de la LGC y 17 letra e) y 26 del RLGC] y por el consejo de administración [art. 25 de la LGC y 17 letra e) del RLGC];

ii) la participación en la actividad que realiza la cooperativa en la cuantía mínima exigida por los estatutos [arts. $6^{\circ}$ letra e) de la LGC y 17 letra f) del RLGC], sin que quepa ostentar la calidad de socio de organización (art. 33 de la LGC);

iii) la reserva sobre aquellos asuntos y datos cuya divulgación perjudica los intereses lícitos de la cooperativa (arts. 45 y
71 del RLGC), sin perjuicio del deber de informar al órgano fiscalizador competente de aquellos antecedentes que sean de su competencia [art. 17 letra g) de la RLGC];

iv) aceptar y servir los cargos sociales para los que fuere elegido [arts. 2 letras h) yj) y 17 letra c) del RLGC], salvo que se encuentre afectado por alguna de las inhabilidades que le impiden desempeñar el cargo [arts. 30 de la LGC y 2 letra i), $67,73,80,87$ y 88 del RLGC] o ejercer sus derechos sociales [art. 17 letra c) del RLGC];

v) responder de los daños que, con culpa o dolo, cause en el ejercicio de un cargo social (arts. 13, 25, 26, 29 y 62 de la LGC);

vi) el cumplimiento en tiempo y forma de las obligaciones económicas que le correspondan [arts. $6^{\circ}$ letras c) y e) y $31 \mathrm{de} \mathrm{la}$ LGC y 2 letra b), 17 letra a) y 106 del RLGC], las que, debidamente reajustadas (art. $94 \mathrm{del}$ RLGC), pueden ser cobradas judicialmente, sirviendo de título ejecutivo la copia autorizada del acta del consejo de administración en la que conste el acuerdo adoptado sobre dicho cobro judicial, acompañado del documento de suscripción correspondiente (arts. 31 y 36 de la LGC y 96 del RLGC);

vii) no realizar, dentro de la zona de funcionamiento que señalan los estatutos, operaciones de la misma índole de las que ejecute la respectiva cooperati- 
va, ni colaborar con quien las efectúe [arts. 14 de la LGC y 17 letra h) del RLGC];

viii) responder con sus aportes de las obligaciones contraídas por la cooperativa hasta el monto de sus cuotas de participación (art. 32 de la LGC), incluso, de las existentes antes de su ingreso, sin que se admita estipulación alguna en contrario (arts. 18 de la LGC y 97 del RLGC); ix) la concurrencia personal a la junta general, si así se ha establecido en los estatutos [arts. 22 de la LGC y 17 letra b) y 36 del RLGC], y a las actividades educativas que la cooperativa ponga en práctica [art. 17 letra i) del RLGC];

x) la imposibilidad de pertenecer a otra entidad de igual finalidad, si los estatutos contienen tal prohibición (art. 14 de la LGC);

xi) la prohibición de desempeñar cargos directivos en más de una entidad cuando se pertenece a dos o más con igual objeto social (art. 14 de la LGC);

xii) observar una conducta de acuerdo con los principios y finalidades del movimiento cooperativo (art. 1546 del CC);

xiii) mantener actualizados sus domicilios en la entidad [art. 17 letra d) de la RLGC];

xiv) firmar el libro de asistencia cada vez que concurra a la junta general de socios [arts. 17 letra j) y 35 del RLGC];

$\mathrm{xv}$ ) ejercer de buena fe su derecho a renunciar a la cooperativa (art. 1546 del $C$ C) y sólo en aque- llos casos en que así lo permiten los estatutos [arts. 2 letra f), 21 y 22 del RLGC];

xvi) aceptar las responsabilidades y sanciones que le correspondan por las faltas cometidas contra las obligaciones sociales [arts. 15 de la LGC y 2 letra e), 11, 17, 18 y 20 letra f) del RLGC].

Si concurren copulativamente las dos condiciones antes señaladas, el solicitante debe ser aceptado como socio por la cooperativa. La ley sólo establece la imposibilidad de limitar el ingreso de socios por razones políticas, religiosas o sociales (arts. $1^{\circ}$ y 16 de la LGC), sin aludir a las discriminaciones basadas en el sexo o en la raza. La falta de referencia a la prohibición de establecer discriminaciones en razón de raza se explica en cierta medida por la existencia de modalidades asociativas especiales respecto de las etnias indígenas, como las comunidades (párrafo $4^{\circ}$ del título I de la ley $\mathrm{N}^{\circ} 19.253$ ) y asociaciones indígenas (párrafo II del título v de la ley $\mathrm{N}^{\circ} 19.253$ ), o por la especial protección que se brinda a las tierras indígenas (título II de la ley $\mathrm{N}^{\mathrm{o}}$ 19.253), sin perjuicio del derecho de quienes pertenezcan a tales etnias (art. $2^{\circ}$ de la ley $\mathrm{N}^{\circ} 19.253$ ) para constituir cooperativas conforme a las reglas generales (arts. $1^{\circ}$ y $19 \mathrm{~N}^{\circ} 2^{\circ}$ y 15 de la CPR; 55 del CC y 13 de la LGC).

La legítima expectativa de llegar a ser socio de una cooperativa se encuentra protegida por ciertas garantías que aseguran la adecuada concreción del principio de adhesión abierta. Así, formulada la solicitud por el aspirante a socio [art. 13 b) del RLGC], el consejo de administración debe resolver y co- 
municar su decisión en un plazo razonable. Dado que no existe un procedimiento establecido para la tramitación de esta solicitud, para determinar el límite temporal de este plazo razonable bien se puede acudir por analogía al art. 22 del RLGC, que regula el modo de ejercer el derecho de renuncia, y en el que se señala que el consejo de administración tiene un lapso de treinta días contados desde la presentación de la solicitud para pronunciarse sobre ella. Por regla general, el silencio no implica una manifestación de voluntad dotada de contenido y no expresa aceptación ni rechazo de una propuesta (cfr. arts. 64 y 65 de la ley $\mathrm{N}^{\circ} 19.880$ ).

Si la solicitud es aprobada, el aspirante habrá de adquirir a cualquier título cuotas de participación en la cooperativa, según lo dispuesto en los estatutos [art. 13 b) del RLGC]. También, si así se establece en los estatutos o lo acuerda la junta general, quien sea aceptado como socio debe pagar una cuota de incorporación (art. 106 del RLGC). Por el contrario, si el consejo de administración rechaza el ingreso de una determinada persona a la cooperativa, debe fundar su decisión en razones objetivas relacionadas con las dos condiciones precedentemente mencionadas [arts. 16 de la LGC y 13 b) del RLGC].

$\mathrm{Si}$ el aspirante que es rechazado por el consejo de administración estima que reúne las condiciones para ser socio y que la decisión de aquél ha sido arbitraria, puede reclamar de esa resolución ante la junta general de socios (arg. ex art. 20 del RLGC). Denegada la admisión por ésta, el solicitante podrá recurrir al procedimiento sumario ante la justicia ordinaria o, bien, a arbitraje, a su elección, para que en esa sede se resuelva el conflicto surgido sobre la interpretación, aplicación, validez o cumplimiento de la normativa vigente (arg. ex art. 114 de la LGC).

El Derecho chileno no se refiere directamente a las cooperativas de segundo grado (cfr. art. 83 del LMCAL), aunque el término no es ajeno a su sistema. En el art. 22 de la LGC, por ejemplo, se dice que los estatutos pueden disponer que la asistencia a la junta general sea siempre personal y que no se admita, en ningún caso, la posibilidad de delegar la facultad de asistir a ellas. Sin embargo, se permite que, cuando así lo establezcan los estatutos, las juntas generales de las cooperativas de primer grado se puedan constituir por delegados

i) si la cooperativa actúa a través de establecimientos ubicados en diversos lugares del territorio nacional o

ii) si ella tiene más de dos mil socios.

Hay, asimismo, un reconocimiento implícito a las cooperativas de segundo grado en el art. 13 de la LGC, que dispone que pueden ser socios de una cooperativa tanto las personas naturales como la personas jurídicas de Derecho Público o Privado, categoría esta última en la que se incluyen las propias cooperativas (art. $5^{\circ}$ de la LGC).

La calidad de socio sólo se pierde:

i) por la muerte (o por la pérdida de la personalidad jurídica, si el socio reviste ese carácter),

ii) por exclusión,

iii) por renuncia,

iv) por la transferencia de todas las cuotas de participación y 
v) por el ejercicio del derecho a retiro (arts. 19 de la LGC y 20 del RLGC).

Asimismo, en las cooperativas de servicios de vivienda o de veraneo de descanso, la calidad de socio se pierde por la imputación de todo el valor de sus cuotas de participación a la adquisición del dominio de un bien raíz habitacional [art. 20 d) del RLGC]. De igual forma, el consejo de administración puede aceptar la reducción o retiro parcial de los aportes hechos por los socios, sin que éstos pierdan la calidad de tales y de acuerdo con las normas que al efecto establezcan los estatutos (art. 37 de la LGC).

\section{AsPectos FinANCIERos}

La financiación de las cooperativas supone considerar cuatro vías de ingreso de capital:

1) las aportaciones de los socios,

2) la creación de reservas,

3) la inversión del remanente y

4) las aportaciones extraordinarias.

\section{Las aportaciones de los socios}

Toda cooperativa debe contar con un capital para iniciar sus actividades [art. $6^{\circ} \mathrm{c}$ ) de la LGC]. Este capital es variable e ilimitado, a partir del mínimo que fijen los estatutos, y se forma con las sumas que paguen los socios por la suscripción de sus cuotas de participación. Los estatutos fijarán el monto mínimo de los aportes que deben efectuar los socios para incorporarse o mantener su calidad de tales (arts. 31 de la LGC y 98 del RLGC).
La contribución de los socios se expresa en cuotas de participación, cuyo valor es aquél que resulta de la suma del monto de sus aportes de capital, más las reservas voluntarias y más o menos, según corresponda, el ajuste monetario señalado en los arts. 34 III de la LGC y 101 del RLGC, y los excedentes o pérdidas existentes, dividido por el total de cuotas de participación emitidas al cierre del período. Las cuotas de participación tienen entre sí igual valor, salvo que se hubiesen emitido cuotas de distintas series, en cuyo caso serán las cuotas de una misma serie las que tendrán igual valor (art.90 del RLGC). El valor de las cuotas de participación se corrige monetariamente y se actualiza en forma anual, considerando para tal efecto la conformación del patrimonio de la cooperativa una vez aplicado el acuerdo de la junta general de socios que se haya pronunciado sobre el balance, en lo relativo a la distribución del remanente o, en su caso, la absorción de las pérdidas (arts. 31 y 34 de la LGC, 90 y 101 del RLGC y $17 \mathrm{~N}^{\circ} 1^{\circ}$ DL 824/1974).

En principio, ningún socio puede ser propietario de más de un 20\% del capital de una cooperativa, salvo en los casos ya mencionados de las cooperativas de ahorro y crédito y especiales agrícolas y de abastecimiento de energía eléctrica (arts. 17 y 95 de la LGC). Las cuotas de participación suscritas, y parcialmente pagadas, gozan de los derechos al pago del interés sobre el capital, si así lo permiten los estatutos, a la devolución de los aportes y a los excedentes provenientes de operaciones con personas que no sean socios, en proporción a la parte efectivamente 
pagada (art. 95 del RLGC). Por excepción, en las cooperativas abiertas de vivienda y de ahorro y crédito, los estatutos y los acuerdos de las juntas generales de socios no pueden acordar el pago anticipado de intereses, así como tampoco la celebración de pactos sobre ellos en forma previa al conocimiento de los resultados del ejercicio anterior por parte de la respectiva junta general (art. 158 del RLGC).

A diferencia de lo que ocurre en otros países ${ }^{2}$, en Chile no se contempla la figura de un socio inversor que posibilite la constitución y puesta en marcha de la propia cooperativa o de un negocio en particular. Esta omisión se intenta subsanar mediante un extenso proyecto de reforma de la LGC actualmente en discusión en el Congreso $\mathrm{Nacional}^{3}$, entre cuyas innovaciones se contiene la inclusión de esta clase de socio para favorecer el acceso de estas entidades a fuentes adicionales de financiación. De esta manera, el proyecto modifica los arts. 17 y 95 de la LGC con el objetivo de permitir que un socio pueda ser propietario de hasta un $40 \%$ del capital de una cooperativa, sin importar su clase. Incluso, se admite que se sobrepase este porcentaje hasta el doble sólo para efectos de su constitución y por un plazo que no podrá exceder de un año contado desde que ella se concrete. En cualquiera caso, se mantiene la premisa de identificación un socio-un voto, impidiendo que el socio inversor adquiera la mayoría absoluta en términos de capital. Además, el proyecto

\footnotetext{
${ }^{2}$ Cfr. art. 21 de la LMCAL.

${ }^{3}$ Mensaje de 4 de enero de 2012, Boletín No. $8132-26$
}

permite que sólo para la constitución de una cooperativa, un socio pueda aportar hasta el 80\% del capital. Tal inversionista tiene el plazo de un año para rebajar su capital al máximo permitido en la ley.

La persona que haya perdido la calidad de socio por renuncia o exclusión, así como los herederos del socio fallecido, tienen derecho a la devolución del monto actualizado de sus cuotas de participación, con las modalidades establecidas en los estatutos (arts. 19 de la LGC y 24 y 25 del RLGC). En caso de liquidación de la cooperativa, una vez absorbidas las eventuales pérdidas, pagadas las deudas y reembolsado a cada socio el valor actualizado de sus cuotas de participación, las reservas legales y cualesquiera otros excedentes resultantes se distribuirán entre los socios, a prorrata de sus cuotas de participación (art. 40 de la LGC).

Cuando prosperan, las cooperativas pueden crear reservas derivadas de las ganancias obtenidas merced a las actividades de la organización. Normalmente, todas, o al menos una proporción bastante grande de estas ganancias, son de propiedad colectiva, dado que representan los logros conjuntos de los socios en apoyo de la entidad a la que pertenecen. En muchos casos, este capital colectivo no se distribuye entre los socios si la cooperativa deja de existir, sino que se destina a empresas comunitarias u otras cooperativas asociadas. Es lo que ocurre con la porción del patrimonio que se ha originado gracias a las donaciones recibidas por la cooperativa, las que deben ser destinadas al objeto que señalen los estatutos. A falta de mención expresa, 
corresponde a la subsecretaría de Economía destinar esos bienes a favor de una o más cooperativas (art. 40 de la LGC). La única excepción la constituyen los terrenos adquiridos a título gratuito por las cooperativas cerradas de vivienda, que se consideran parte de su capital para los efectos de la adjudicación de viviendas a los socios (art. 81 de la LGC).

\section{La creación de reservas}

Las reservas tienen por objetivo proporcionar una mayor estabilidad económica a la cooperativa, conservar su capital social y dar una mayor garantía patrimonial a los acreedores y los socios (art. 100 del RLGC). Según su fuente, estas reservas pueden ser de tres clases:

a) legal,

b) voluntaria y

c) especial

a) La reserva legal es aquélla que deben constituir e incrementar cada año las cooperativas abiertas de vivienda y las de ahorro y crédito, con un porcentaje no inferior al 20\% de sus remanentes (art. 34 de la LGC). Esta reserva se destina principalmente a cubrir las pérdidas de un ejercicio económico y asegurar la normal realización de las operaciones de la cooperativa [art. 100a) del RLGC]. Cuando el fondo de reserva legal alcance un $50 \%$ del patrimonio, estas entidades están obligadas a distribuir entre los socios, a título de excedentes, al menos el 30\% de los remanentes. El saldo, incrementar el fondo de reserva legal o se destina a reservas voluntarias (art. 38 de la LGC). Además, estas cooperativas han de tener invertido, a lo menos, el 10\% de su patrimonio en los activos e instrumentos de fácil liquidación enumerados en el art. 160 del RLGC. Este porcentaje puede ser aumentado mediante una norma de aplicación general por la Dirección de Cooperativas (art. 39 de la LGC).

b) Las reservas voluntarias son aquéllas constituidas o incrementadas anualmente por acuerdos de las juntas generales de socios que se hayan pronunciado acerca de la distribución del remanente generado en los ejercicios anteriores, y aquellas establecidas por los estatutos de una cooperativa. El destino de estas reservas será el que fijen los estatutos o el que acuerde la junta general de socios [art. 100b) de la RLGC]. Las reservas voluntarias no pueden exceder el 15\% del patrimonio de la cooperativa (art. 38IV LGC) y se forman con independencia de la reserva legal cuando hubiere lugar a ella [arts- 38 de la LGC y 100b) del RLGC].

c) La reserva especial se constituye en todas aquellas cooperativas que no tiene obligación de crear una reserva legal, y se incrementa con las donaciones, las devoluciones de excedentes no retirados por los socios dentro del plazo de cinco años, contados desde la fecha en que se acordó su pago, y los fondos sin destinación específica que perciba la 
entidad (art. 100 del RLGC). En las cooperativas obligadas a constituir una reserva legal (art. 34 de la LGC), y salvo que los estatutos dispongan algo distinto, estos bienes pasan a formar parte de dicha reserva (art. 100 del RLGC).

\section{La inversión del remanente}

El remanente es el saldo favorable del ejercicio económico, que se determina mediante un balance confeccionado según las normas y principios contables de general aceptación y las disposiciones legales aplicables a los distintos tipos de cooperativas (art. 104 del RLGC). Este saldo se destina a alguna de las siguientes finalidades:

i) absorber pérdidas acumuladas, hasta concurrencia de su monto;

ii) constituir o incrementar los fondos de reserva legal en los casos que proceda o, bien,

iii) las reservas voluntarias, de acuerdo con lo dispuesto en los estatutos y los acuerdos de la junta general de socios;

iv) distribuir entre los socios un interés al capital, en la forma establecida en los respectivos estatutos o acordada por la junta general de socios;

v) el saldo, si lo hubiese, se denomina excedente y debe ser distribuido entre los socios, o da lugar a una emisión liberada de cuotas de participación, según acuerde la junta general que se ha de pronunciar sobre el balance del ejercicio anterior (arts. 38 de la LGC y 104 del RLGC).

Cuando la cooperativa está dividida en secciones, el remanente de cada una de ellas se distribuye de la forma antedicha (art. 107 del RLGC).

\section{Las aportaciones extraordinarias}

Por acuerdo de la junta general, el todo o parte de las pérdidas que no alcanzaren a ser cubiertas por el remanente del ejercicio, puede ser absorbida por alguna de las partidas siguientes en el orden que se indica:

i) el fondo de reserva legal,

ii) las reservas voluntarias y

iii) el capital aportado por los socios (art. 105 del RLGC).

Asimismo, para la financiación de sus gastos ordinarios y extraordinarios las cooperativas tienen la posibilidad de imponer a sus socios el pago de cuotas sociales y comisiones adicionales, de conformidad con lo que establezcan los estatutos. Dichas cuotas sólo podrán ser cobradas cuando así se hubiese señalado en ellos o, en su defecto, cuando lo acuerde la junta general. Estos aportes no están sujetos a reembolso e incrementan los ingresos no operacionales de la cooperativa (art. 106 del RLGC).

En caso de que sea obligatorio que los socios concurran a la suscripción y pago de las cuotas de participación necesarias para efectuar un aumento de capital, es necesario que dicho aumento sea aprobado previamente por una junta general [art. 23m) de la LGC]. Además, y antes de proceder a tal aumento, la cooperativa debe capitalizar los intereses y excedentes que no se hubiesen distribuido mediante la emisión 
de cuotas de participación liberadas de pago, a menos que la junta que se haya pronunciado sobre el aumento de capital establezca una regla distinta. La junta general también puede acordar aumentos de capital que no sean obligatorios para todos los socios, estableciendo las normas y modalidades para que quienes concurran a suscribir y pagar los nuevos aportes (arts. $31 \mathrm{de}$ la LGC y 99 del RLGC). Para obtener financiación, la junta general puede autorizar igualmente la emisión de valores de oferta pública según la ley $\mathrm{N}^{\mathrm{O}}$ 18.045 (art. 35 de la LGC).

\section{GobIERNO COOPERATIVO}

La dirección, administración, operación y vigilancia de las cooperativas está a cargo de los siguientes órganos:

1) la junta general de socios,

2) el consejo de administración,

3) el gerente $y$

4) la junta de vigilancia (art. 20 de la LGC).

\section{La junta general de socios}

La autoridad suprema de la cooperativa es la junta general de socios, que se constituye por la reunión de aquéllos que figuren debidamente inscritos en el registro social y en la que se discuten las políticas futuras, se toman las decisiones importantes y se aprueban las acciones concretas a realizar (arts. 21 y 23 de la LGC y 26 del RLGC). Los acuerdos adoptados con sujeción a las disposiciones legales, reglamentarias y estatutarias, son obligatorios para todos los miembros de la cooperativa (arts. 21 de la LGC y 26 del RLGC).
En principio, todo socio tiene la posibilidad tanto de elegir como de ser elegido para el ejercicio de los cargos sociales [arts. $1^{\circ}, 21,23$ c), 24, 28 y 90 de la LGC y 17 c) del RLGC], salvo que se encuentre afecto a alguna causa de inhabilidad [arts. 30 de la LGC y 2 i), 67, 73, 80, 87 y 88 del RLGC] o impedido de ejercer sus derechos sociales [art. 17 c) del RLGC]. La única excepción es que la persona que sea socio de más de una cooperativa de igual finalidad, sólo podrá desempeñar cargos directivos en una de ellas (art. 14 de la LGC). Sin embargo, los estatutos pueden contemplar cláusulas que confieran a las personas jurídicas de derecho público o privado que participen en una cooperativa el derecho a designar un determinado número de miembros del consejo de administración; pero este privilegio se reduce sólo a una minoría de ellos. Asimismo, los estatutos pueden contemplar la participación de los trabajadores de la cooperativa en su consejo de administración. El único límite contemplado para estas dos situaciones es que al menos el 60\% de los integrantes titulares y suplentes del consejo de administración ha de ser elegido por los socios usuarios de la cooperativa (art. 24 de la LGC).

Las grandes cooperativas requieren de sistemas especiales de organización de las juntas generales para hacer posible la plural y variada participación de los socios. Para evitar una desnaturalización del principio de gestión democrática, la ley y su reglamento se ocupan de la representación en junta general y establecen al efecto una serie de reglas, a saber:

i) los poderes para asistir con derecho a voz y voto en dichas 
juntas deben ser otorgados por carta poder simple (arts. 22 de la LGC y 36 del RLGC);

ii) los apoderados han de ser socios de la cooperativa, salvo que se trate del cónyuge o hijos del socio, o de administradores o trabajadores de éstos, en cuyo caso el poder tiene que ser autorizado ante notario y dura dos años (arts. 22 de la LGC y 36 del RLGC);

iii) sin embargo, no podrán ser apoderados los miembros del consejo de administración o de la junta de vigilancia, el gerente y los trabajadores de las cooperativas (art. 22 de la LGC);

iv) ningún socio puede representar a más de un 5\% de los socios presentes o representados en una asamblea general (art. 22 de la LGC);

v) los estatutos de una cooperativa pueden disponer, en fin, que la asistencia a junta general sea personal y que no se acepte, en ningún caso, mandato para asistir a ellas (arts. 22 de la LGC y 36 del RLGC).

Las reglas anteriores tienen un régimen distinto tratándose de las juntas generales de ciertas cooperativas de primer grado. En ellas, y si así lo establecen los estatutos, las juntas generales se pueden constituir por delegados cuando la cooperativa actúe a través de establecimientos ubicados en diversos lugares del territorio nacional o, bien, cuando ésta tenga más de dos mil socios. Estos delegados deben ser socios de la cooperativa (arts. 22 de la LGC y 49 del RLGC), han de ser elegidos por asambleas locales antes de la junta general de socios (arts. 22 de la LGC y 47 del RLGC), representan a los socios de sus respectivas asambleas ante la junta general, en proporción al número de socios que integra la asamblea que los haya elegido (art. $48 \mathrm{del}$ RLGC), y permanecen en sus cargos el tiempo que se señale en los respectivos estatutos, no pudiendo en caso alguno prolongarse su período por más de un año, sin perjuicio de la posibilidad de ser reelegidos indefinidamente (arts. 22 de la LGC y 51 del RLGC).

La participación de los socios se rige por el principio "una persona, un voto" (arts. $1^{\circ}$ y 22 de la LGC y 48 del RLGC). No hay ninguna norma que altere este criterio para las cooperativas de segundo grado, contempladas sólo de forma implícita en la ley (arts. 13 y 22 de la LGC). La única excepción es el sistema de voto ponderado que se permite en las cooperativas especiales (art. 99 de la LGC). Para aplicar este sistema, con treinta días de anticipación a la celebración de una junta general, el consejo de administración debe proceder al cierre de los registros para determinar los socios que a esa fecha tienen derecho a voto. Enseguida, ha de fijar el total máximo de votos que se pueden emitir, el que deberá ser múltiplo de tres y no inferior a diez veces el número de socios con derecho a voto. Dicho total se distribuirá entre estos últimos en esta forma:

i) un tercio se prorrateará por persona entre todos los socios;

ii) un tercio se distribuirá entre los socios a prorrata de las operaciones efectuadas por ellos 
con la cooperativa duranteel último ejercicio, determinándose las operaciones por uno o más de los siguientes factores, según lo establezcan los estatutos: su cuantía en valores constantes, los márgenes brutos que ellas hayan significado como ingresos para la cooperativa y su volumen en unidades físicas de productos entregados a la cooperativa o adquiridos a ésta;

iii) un tercio se distribuirá entre los socios a prorrata del número de acciones que posean. Para su contabilización, las fracciones de votos se despreciarán si el cociente resultare con una fracción igual o inferior a media unidad.

\section{El consejo de administración}

El consejo de administración, que es elegido por la junta general de socios, tiene a su cargo la administración superior de los negocios sociales y representa judicial y extrajudicialmente a la cooperativa para el cumplimiento del objeto social, sin perjuicio de la representación que compete al gerente (art. 24 de la LGC). Si nada se indica en los estatutos, el consejo de administración se compondrá de tres miembros titulares, los que se renovarán íntegramente cada dos años en sus cargos, y podrán ser reelegidos de modo indefinido (art. 54 del RLGC). Cualquier persona puede ser elegida para el cargo de consejero. Incluso, los estatutos pueden prever la participación de los trabajadores de la propia cooperativa en su consejo de administración (art. 24 IV de la LGC).
La única limitación es que al menos el $60 \%$ de los consejeros titulares y suplentes sean elegidos por los socios usuarios de la cooperativa (art. $24 \mathrm{v}$ de la LGC). Los acuerdos del consejo de administración deben ser adoptados en forma colectiva en sesión legalmente constituida (art. 62 del RLGC).

\section{El gerente}

El gerente es el ejecutor de los acuerdos y órdenes del consejo de administración y representa judicialmente a la cooperativa (arts. 27 de la LGC y 84 del RLGC). Las cooperativas de trabajo están dispensadas de la obligación de designar un consejo de administración si no superan los diez socios. Cuando se omita dicha designación, el gerente será nombrado por la junta general de socios y gozará de las atribuciones que la ley y su reglamento confieren al consejo de administración. La junta general puede disponer, empero, que el gerente desempeñe todo o parte de las atribuciones correspondientes al consejo de administración junto con uno o más socios que se individualizarán al efecto (art. 61 de la LGC).

\section{La junta de vigilancia}

La junta de vigilancia aplica al interior de las cooperativas el principio político de los frenos y contrapesos en el ejercicio del poder de gobierno. Ella se compone de cinco miembros nombrados por la junta general, dos de los cuales pueden ser personas ajenas a la cooperativa que cumplan los requisitos establecidos en el art. 80 del RLGC. Su función es examinar la contabilidad, 
inventario, balance y demás estados financieros de la cooperativa, así como las demás atribuciones que se establezcan en los estatutos y en el reglamento (arts. 28 de la LGC y 72 del RLGC). Función similar desempeñan los auditores externos, que por su propio carácter deben ser ajenos a las cooperativas que auditen (art. 119 del RLGC). Su tarea consiste igualmente en examinar los antecedentes contables y financieros de la cooperativa, y expresar su opinión profesional e independiente sobre ellos (art. 121 del RLGC). En las cooperativas de ahorro y crédito es necesario contar, además, con un comité de crédito, cuyos miembros son designados por el consejo de administración (art. 90 de la LGC).

Además de la inscripción en el Registro de Comercio correspondiente requerida como solemnidad de constitución (art. $7^{\circ}$ de la LGC), las cooperativas deben inscribirse en el registro que lleva el Departamento de Cooperativas; dicho organismo podrá objetar el contenido del acta de constitución o sus extractos, si infringen normas legales o reglamentarias (arts. $9^{\circ}$ y 10 del RLGC).

Las cooperativas se encuentran sujetas a la supervisión del Ministerio de Economía, Fomento y Turismo, quien la ejerce a través del Departamento de Cooperativas dependiente de la Subsecretaría de Economía (capítulo IV de la LGC y título IX del RLGC). Este departamento tiene las siguientes atribuciones:

i) promover el sector cooperativo a través de programas des-

tinados al desarrollo de la gestión y capacidad empresarial de las cooperativas;

ii) dictar normas que contribuyan al perfeccionamiento del funcionamiento de las cooperativas;

iii) llevar un registro de las cooperativas vigentes;

iv) ejercer la supervisión y fiscalización de las cooperativas en la forma señalada por la ley, especialmente aquéllas de importancia económica (cooperativas de ahorro y crédito y abiertas de vivienda, así como todas aquellas cuyos activos seaniguales o superiores a $50.000 \mathrm{UF}$ o tengan más de quinientos socios);

v) elaborar estadísticas del sector y difundir la información de que disponga (arts. 108 y 109 de la LGC).

Otro organismo que ejerce algún grado de vigilancia sobre las cooperativas es el Servicio de Impuestos Internos, dado que ellas gozan de una serie de privilegios y exenciones tributarias (título viI de la LGC y art. 17 DL 824/1974) cuya extensión a terceras personas o fines diversos es necesario controlar (art. $4^{\circ}$ de la LGC).

Fuera de estos organismos de control general, las cooperativas se sujetan, en cuanto a las operaciones propias de su giro y en lo que les sea aplicable, a la regulación y fiscalización establecida por las leyes especiales que rijan la actividad económica que desarrollan (art. $2^{\circ}$ II de la LGC). Eso explica que existan cooperativas que, por su concreta actividad, se encuentran relacionadas con 
la administración pública a través de otro tipo de relaciones. Es el caso, por ejemplo, de las cooperativas de abastecimiento y distribución de energía eléctrica, que se rigen además por el DFL 1/1982, del Ministerio de Minería (arts. 72 de la LGC y 161 del RLGC); o de las cooperativas de ahorro y crédito, que sólo pueden realizar las actividades enumeradas en el art. 86 de la LGC bajo las condiciones, requisitos y modalidades que establezca el Banco Central de Chile. Asimismo, para la realización de las operaciones mencionadas en el art. 86 b), h), i), k) y n) de la LGC, las cooperativas de ahorro y crédito deben contar con un patrimonio pagado igual o superior a 400.000 UF y encontrarse sometidas a la fiscalización de la Superintendencia de Bancos e Instituciones Financieras (art. 87 de la LGC). A esta misma fiscalización queda sujeta toda cooperativa de ahorro y crédito cuyo patrimonio exceda de ese límite, respecto de las operaciones económicas que realice en cumplimiento de su objeto (art. 87 de la LGC).

\section{Modificaciones estructurales}

Las modificaciones estructurales se caracterizan por incidir sobre elementos considerados por el legislador como esenciales al tipo social, con el propósito de adaptar la cooperativa a las exigencias del mercado. Se trata, por tanto, de figuras que tienen en común una misión estratégica, de reorganización técnica de la empresa, y que afectan elementos esenciales de su estructura societaria. Estas alteraciones van más allá de las simples modificaciones es- tatutarias para afectar la organización patrimonial o personal de la cooperativa, y en ellas quedan comprendidas la fusión, la división y la transformación, que vienen tratadas en los títulos vi de la LGC y vi del RLGC.

La ley permite que dos o más cooperativas puedan fusionarse sin liquidarse previamente y reconoce dos formas de concretar esta modificación estructural: la fusión por creación y la fusión por incorporación (art. 45 de la LGC). Hay fusión por creación, cuando el activo y pasivo de dos o más cooperativas que se disuelven, se aporta a una nueva cooperativa que se constituye con ese propósito (art. 45III de la LGC). Hay fusión por incorporación, cuando una o más cooperativas que se disuelven son absorbidas por una cooperativa ya existente, la que adquiere todos sus activos y pasivos (art. 45IV de la LGC).

La división consiste, por su parte, en la distribución del patrimonio de la cooperativa entre sí y una o más cooperativas que se constituyan al efecto, correspondiéndoles a los socios de la cooperativa dividida la misma proporción en el capital de cada una de las nuevas entidades que aquélla que poseía en la cooperativa que se divide (art. 46II de la LGC).

En fin, la transformación es la modificación de los estatutos de una cooperativa con el propósito de someterla a un régimen jurídico aplicable a otro tipo social, subsistiendo su personalidad jurídica (art. 46III de la LGC).

La decisión de fusionarse, dividirse o transformarse debe ser acordada por una junta general de socios convocada al efecto en cada una de las cooperativas que participan en el proceso [art. 23e) 
de la LGC]. En forma previa a la adopción de ese acuerdo de fusión, división o transformación, se han de someter a la consideración de la junta general de socios los siguientes documentos:

i) los balances de la o las cooperativas involucradas;

ii) los estados de resultados correspondientes;

iii) una memoria explicativa que refleje el real estado económico de la empresa y

iv) los informes periciales que procedieren (arts. $45 \mathrm{VI}$ y viII y $46 \mathrm{IV}$ de la LGC y 122I del RLGC). Dichos antecedentes deberán ser presentados por profesionales independientes, y su antigüedad no podrá ser superior a los sesenta días anteriores a la fecha de la junta convocada para acordar la fusión, división o transformación (arts. 45VI y viII y $46 \mathrm{IV}$ de la LGC y 122I del RLGC). Aprobados estos antecedentes y la modificación estructural propuesta, la junta sancionará los estatutos de las cooperativas que subsisten o se crean como consecuencia de aquélla (art. 46VI y viII de la LGC), y se procederá a absorber las pérdidas acumuladas que existan a la fecha de dicho acuerdo (art. 123I del RLGC). Tratándose de una transformación, los nuevos estatutos deberán satisfacer además los requisitos propios del tipo social elegido (art. 97 de la ley $\mathrm{N}^{\mathrm{o}}$ 18.046).

En caso de división de una cooperativa, será necesario partir también las reservas legales, las que pasarán a integrar el patrimonio de aquellas entidades que se creen, en la proporción que estipulen los socios (art. 123II del RLGC). Después de cumplidos estos trámites, el consejo de administración de la nueva cooperativa o de aquélla que subsiste deberá distribuir directamente las nuevas cuotas de participación entre los socios de las entidades fusionadas, divididas o transformadas en la proporción correspondiente (arts. 46VIII de la LGC y 123 III del RLGC). Los excedentes generados por cada cooperativa en el ejercicio en que se realice la fusión o división pertenecerán a los socios de aquélla en que se produjeron y se distribuirán de conformidad con sus propios estatutos (art. 46IX de la LGC). Lo mismo ocurrirá con las reservas legales, que podrán distribuirse según las reglas de la disolución cuando así lo permita el régimen de la entidad que surja tras la fusión o transformación (art. 123III del RLGC).

Como medida de protección se establece que ningún socio, a menos que consienta en ello, podrá perder su calidad de tal, con motivo de la fusión, división o transformación de la cooperativa a la cual pertenece (arts. 45VII y $46 v$ de la LGC). En esta materia, la ley no contempla ninguna regla especial respecto de los activos, las reservas o el capital de una cooperativa que se transforma en una sociedad civil o comercial, por lo que cabe entender que todos ellos pasan a la nueva entidad y quedan sujetos a su régimen jurídico propio. Esta omisión hace suponer que el conflicto de intereses subyacente se resuelve a favor de la autonomía de la voluntad, prefiriéndose la decisión democrática de los socios de sujetarse a una disciplina diferente, sin preservar en la vigencia del principio cooperativo de participación económica. Aun así, por analogía cabe entender que las deu- 
das de las cooperativas han de quedar saldadas de acuerdo con el particular régimen económico de estas entidades (arg. ex art. 98 de la ley $\mathrm{N}^{\circ}$ 18.046).

\section{RÉGIMEN TRIBUtARIO}

Las cooperativas gozan de un régimen tributario más beneficioso que aquél que se aplica a las sociedades en general, y que se manifiesta en una serie de exenciones y particularidades relacionadas con el pago:

1) del impuesto a la renta,

2) el impuesto al valor agregado,

3) los demás impuestos fiscales y

4) las contribuciones, derechos, impuestos y patentes municipales.

\section{El impuesto a la renta}

Por principio, la ley considera que las cooperativas no producen utilidades (art. 53 de la LGC) y, por consiguiente, sólo están afectas al impuesto a la renta por aquella parte del remanente correspondiente a las operaciones realizadas con terceros, el que se determina aplicando la relación porcentual existente entre el monto de los ingresos brutos de las operaciones efectuadas con quienes no sean socios y el monto total de los ingresos de todas las operaciones de la cooperativa (arts. $4^{\circ}, 49$ III y 51 de la LGC y $17 \mathrm{~N}^{\circ} 2^{\circ}$ DL 824/1974). Distinto es el caso de las cooperativas especiales y de las agencias de cooperativas extranjeras constituidas en el país, que se encuentran sometidas al mismo régimen tributario de las sociedades anónimas y los socios al de los accionistas. Para estos efectos, el remanente se considera como utilidad del ejercicio (arts. 100 y 122 de la LGC) y tributa como renta a través de los impuestos de primera categoría (art. 20 DL 824/1974) y global complementario (art. 52 DL 824/1974). Algo similar ocurre con la distribución de excedentes o participaciones entre los socios de una cooperativa de trabajo, que se califican como rentas provenientes de una forma de trabajo dependiente y quedan gravadas con el impuesto único señalado en el art. $42 \mathrm{~N}^{\circ} 1^{\circ} \mathrm{DL} 824 / 1974$ (art. 17 $\mathrm{N}^{\circ} 5^{\circ}$ DL 824/1974). Por lo que atañe al impuesto de primera categoría, los socios no tributan por el mayor valor de sus cuotas de participación (arts. 50 de la LGC y $17 \mathrm{~N}^{\circ} 25$ DL 824/1974), ni por el aumento del valor nominal de éstas o de sus cuotas de ahorro (art. 51 de la LGC), y tampoco deben hacerlo por las operaciones que la cooperativa ha realizado con ellos dentro de su giro habitual (arts. 52 de la LGC y $17 \mathrm{~N}^{\circ} 4^{\circ}$ DL 824/1974), dado que el producto proveniente de ellas se reputa un ingreso no constitutivo de renta (Servicio de Impuestos Internos, oficio $\mathrm{N}^{\mathrm{o}} 549 / 2008$ ). Por el contrario, y de acuerdo con el actual criterio de la autoridad administrativa, los socios sí tributarán por la porción del remanente que reciban de la cooperativa, para cuyo efecto se distingue entre los socios a quienes se aplica un régimen de renta efectiva y aquellos afectos a uno de renta presunta (Servicio de Impuestos Internos, oficio $\mathrm{N}^{\circ}$ 1397/2011).

\section{El impuesto al valor agregado}

Las cooperativas están afectas al impuesto al valor agregado según lo establecido en el DL 825/1974 [art. 49a) de la LGC]. En virtud de este último, los 
servicios que las cooperativas prestan a sus socios dentro de su objeto específico quedan fuera del hecho gravado con dicho impuesto (art. $5^{\circ}$ II DS 55/ 1977, del Ministerio de Hacienda), pero no así las ventas que aquéllas realice a favor de éstos en la medida que satisfagan el supuesto del art. $2^{\circ} \mathrm{N}^{\mathrm{o}} 1^{\circ}$ DL 825/1974.

\section{Los demás impuestos fiscales}

Las cooperativas están exentas de la totalidad de los impuestos contemplados en el DL 3475/1980 en todos los actos relativos a su constitución, registro, funcionamiento interno y actuaciones judiciales [art. 49b) de la LGC]. Igualmente, las cooperativas escolares están exentas de todos los impuestos fiscales y municipales, con la salvedad del impuesto al valor agregado en las condiciones antedichas (art. 70II de la LGC).

\section{Las contribuciones, derechos, impuestos y patentes municipales}

Sin importar su clase, las cooperativas están exentas, asimismo, del 50\% de todas las contribuciones, derechos, impuestos y patentes municipales, salvo los que se refieren a la elaboración o expendio de bebidas alcohólicas y tabaco [art. 49c) de la LGC], y, residualmente, de cualquier otra contribución, impuesto, tasa y demás gravámenes impositivos en favor del fisco [art. 49a) de la LGC].

\section{INSTANCIAS DE INTEGRACIÓN Y COLABORACIÓN}

Bajo la denominación de integración cooperativa se suelen comprender las diferentes técnicas jurídicas que facilitan la concentración entre cooperativas, sea mediante fórmulas caracterizadas por la unión económica de las entidades participantes, sea a través de lazos de colaboración y ayuda recíproca. La materia aboca así en dos cuestiones relevantes:

1) la posibilidad de constituir gru pos cooperativos y

2) la congregación de las cooperativas en estructuras de grado superior.

\section{Los grupos cooperativos}

En principio, no existe ningún impedimento para que las cooperativas se integren en un grupo empresarial (títulos XV y XXV de la ley $\mathrm{N}^{\mathrm{O}} 18.045$ ). La única limitación es la imposibilidad de establecer con ellos combinaciones o acuerdos que hagan participar a éstos directa o indirectamente de los beneficios tributarios o de otro orden que el Derecho Cooperativo otorgue a estas entidades (art. $4^{\circ}$ de la LGC).

A diferencia de otras legislaciones, la ley chilena no se ocupa en especial de los grupos cooperativos como modalidad diferenciada ${ }^{4}$. Sin embargo, la idea de tal no es por completo ajena a su sistema, como lo demuestra el hecho de que el art. 23 de la LGC contiene dos referencias a las filiales de una cooperativa al tratar de las materias que son de conocimiento de la junta general de socios. También se permite que una persona jurídica pueda ser socio de una cooperativa (art. 13 de la LGC) y se alude a la participación de las cooperativas

${ }^{4}$ Véase, por ejemplo, el art. 78 de la Ley española de cooperativas de 1999. 
en otras cooperativas o sociedades (art. 41 de la LGC). Otra referencia indirecta al concepto de grupo empresarial se encuentra en el art. 85 del RLGC, donde se señala que, conforme dispongan los estatutos, el gerente de una cooperativa no puede realizar en forma particular actividades que compitan o sean similares con el giro propio de la entidad para la que trabaja o de sus empresas relacionadas.

Pese a que es usual concebir los grupos cooperativos como estructuras paritarias, a partir de las referencias legales antes mencionadas cabe concluir que en Chile una cooperativa puede ser cabeza de un grupo jerárquico, el que puede estar integrado sólo por esta clase de entidades o también por otras clases de sociedades. Nada impide, además, que se produzca la situación inversa, vale decir, que una cooperativa forme parte de un grupo jerárquico como sociedad dominada, dado que cualquier persona, natural o jurídica, puede ser socio de una cooperativa (art. 13 de la LGC). En tal caso, empero, el problema estriba en determinar si una persona puede ostentar el carácter de controlador respecto de una cooperativa, dado que en ellas la regla general es un voto por persona (arts. $1^{\circ}$ y 22 de la LGC).

El art. 97 LMV describe al controlador de una sociedad como toda persona o grupo de personas con acuerdo de actuación conjunta que, directamente o a través de otras personas naturales o jurídicas, participa en su propiedad y tiene poder para asegurar la mayoría de votos en la respectiva asamblea y elegir a la mayoría de los directores o administradores, o bien para influir en forma decisiva en la administración de la sociedad. Dos son, pues, las formas de convertirse en controlador, y dos también las características de quien puede ostentar esa calidad.

En primer término, es controlador quien participa en la propiedad de una sociedad y tiene poder para asegurar la mayoría de votos en la respectiva asamblea y elegir a la mayoría de los directores o administradores. En segundo término, lo es también quien puede influir decisivamente en la administración de la sociedad, como ocurre cuando se detenta al menos un 25\% del capital con derecho a voto, o de la totalidad del capital si no se trata de una sociedad por acciones (art. 99 de la LMV). Ahora bien, la calidad de controlador se ostenta tanto de forma personal como colectiva, de manera que puede serlo una sola persona o varias vinculadas entre sí por un acuerdo de actuación conjunta, mediante el cual se comprometen a participar con idéntico interés en la gestión de la sociedad u obtener el control de la misma (art. 98i de la LMV).

En una cooperativa es imposible que una sola persona tenga poder suficiente para asegurar la mayoría de los votos en la junta general o para elegir a la mayoría de los miembros del consejo de administración, porque lo impide el principio de gestión democrática que las inspira (art. $1^{\circ} \mathrm{II}$ de la LGC). La única posibilidad de controlar una cooperativa consiste, entonces, en que varias personas se unan merced a un acuerdo de actuación conjunta. En principio, tal acuerdo adolecerá de nulidad absoluta si supone un conflicto con el mentado principio de gestión democrática (arts. 10, 1466, 1467,1681 y 1682 del $C$ C). Esto signi- 
fica que valdrá como tal cuando no lo contravenga, como acaece cuando los socios que lo han celebrado suman un número de votos suficiente para adoptar las decisiones de la cooperativa con respeto a la mayoría democrática. Además, la ley $\mathrm{N}^{\mathrm{o}} 18.045$ presume que existe acuerdo de actuación conjunta:

i) entre representantesy representados;

ii) entre una persona y su cónyuge o sus parientes hasta el segundo grado de consanguinidad o afinidad;

iii) entre entidades pertenecientes a un mismo grupo empresarial $\mathrm{y}$

iv) entre una sociedad y su controlador o cada uno de sus miembros (art. 98II).

Las tres primeras situaciones son perfectamente posibles respecto de una cooperativa, no así la cuarta.

\section{La congregación de cooperativas en estructuras de superior grado}

La otra modalidad de colaboración entre cooperativas es su congregación en estructuras de grado superior, sin importar la naturaleza que revistan o el nombre que se les asigne.

Esta modalidad de integración tiene una larga historia en el cooperativismo chileno y es considerada por la ley como una de las características fundamentales de esta clase de asociaciones (art. $1^{\circ}$ de la LGC). Las dos primeras organizaciones de integración cooperativa fueron creadas al amparo de la ley $\mathrm{N}^{\circ} 4.058$, como fue el caso de la FECRECOOP, 1945, y de la FECOVIP, 1958; mientras que las dos siguientes nacieron bajo el imperio del decreto reglamentario 20/1963 de la Corporación de Reforma Agraria, como ocurrió con la FENACOPEL, 1963, y el CECOOP, 1963. El mayor incentivo a esta forma de cooperación se produjo, empero, durante el gobierno del presidente Eduardo Frei Montalva (19641970), período en el que se dio un particular impulso a la labor de organismos estatales que favorecieron de manera directa o indirecta el desarrollo de las cooperativas, como la CORA y el INDAP, ambos creados al amparo de la ley $\mathrm{N}^{\mathrm{O}}$ 15.020. En este período nació, además, el Departamento de Desarrollo Cooperativo del SERCOTEC, 1967, y se constituyeron dos organizaciones de integración cooperativa de gran importancia, como fueron el IFICOOP, 1964 y la CONFECOOP-CHILE LIMITADA, 1969; y otras de menor alcance, como la INVICOOP, 1969, el AUDICOOP, 1970 y la CAMPOCOOP, 1970.

Cabe también incluir aquí otras figuras atípicas surgidas del asociacionismo cooperativo, cuya función es constituir una plataforma de defensa y promoción del sector. Por su importancia conviene destacar la reciente creación del Foro Empresarial Cooperativo (2011), que agrupa a las diez principales cooperativas del país (COLUN, CAPEL, COOPEUCH, CONAVICOOP, CREO, CALS, CONGARANTÍA, COOCRETAL, FINAGRA y CHILECOOP). Ellas representan aproximadamente a seiscientos mil socios, aportan más del 1,13\% de PIB del país y sus activos alcanzan los USD\$ 2.900.000.000, además de conformar una fuerza laboral cercana a los cinco mil trabajadores. 
Según ha quedado dicho, la actual LGC no trata de las cooperativas de segundo grado con ese nombre ${ }^{5}$, aunque el término no es ajeno a su sistema (art. 22 de la LGC). La regla general contenida en el art. 13 de la LGC es que pueden ser socios de una cooperativa tanto las personas naturales como las personas jurídicas de derecho público o privado. Esto significa que los únicos límites de incorporación son el porcentaje máximo de participación en el capital (arts. 17 y 95 de la LCG), la prohibición de crear cuotas de participación de organización y privilegiadas (art. 33 de la LGC) y los derivados de la clase de cooperativa de que se trata. Así también, la ley reconoce la posibilidad de constituir filiales [art. $23 \mathrm{~h}$ ) y n) de la LGC], entendiendo por tales aquellas organizaciones en que una cooperativa controla directamente, o a través de otra persona natural o jurídica, más del 50\% de su capital [art. 23 h) de la LGC]; y el hecho de que éstas puedan encontrarse relacionadas con otras empresas (arts. 42 de la LGC, 95 del RLGC y 100 de la ley $N^{0} 18.045$ ).

De la integración cooperativa trata específicamente el capítulo III de la LGC (arts. 101-107) y el título vIII del RLGC (arts. 162-164), donde se prevé la creación de federaciones, confederaciones e institutos auxiliares. Estos últimos son entidades destinadas a proporcionar servicios de asesoría, técnicos, educacionales y económicos preferentemente a las cooperativas, federaciones, confederaciones, grupos precooperativos y a otros institutos auxiliares, pudiendo, asimismo, participar en la organización de industrias y servicios de

\footnotetext{
${ }^{5}$ Cfr. art. 83 de la LMCAL.
}

cualquiera naturaleza, en beneficio de las cooperativas y de los socios de éstas (art. 104 de la LGC). Por su parte, las federaciones y confederaciones tienen por finalidad velar por los intereses y complementar y facilitar el cumplimiento de los objetivos de las entidades que las componen, cooperando con su labor y realizando al efecto cualesquiera actividad de producción de bienes o de prestación de servicios que se señale en sus estatutos (art. 103 de la LGC).

La diferencia entre estas distintas instancias de integración federativas es su composición. Según el art. 101 de la LGC, las federaciones están constituidas por tres o más cooperativas, las confederaciones por tres o más federaciones, y los institutos auxiliares por siete o más personas jurídicas de Derecho Público, cooperativas u otras personas jurídicas de Derecho Privado que no persiguen fines de lucro (corporaciones, fundaciones, asociaciones gremiales, sindicatos, juntas de vecinos, organizaciones comunitarias, asociaciones indígenas, mutualidades y asociaciones constituidas merced a la ley $\mathrm{N}^{\mathrm{O}}$ 20.500). A las dos primeras pueden pertenecer también como socios otras personas jurídicas de Derecho Público o de Derecho Privado que no persigan fines de lucro. Para todos los efectos legales y reglamentarios, estas tres modalidades de cooperación asociativa se consideran cooperativas (arts. 102 de la LGC y 162 del RLGC) y deben cumplir los encargos que les solicite el organismo fiscalizador o los árbitros que figuren en el Registro de Árbitros confeccionado por la $\mathrm{CON}$ FECOOP-CHILE LIMITADA o por otros organismos de integración cooperativa, aun cuando la cooperativa en 
la cual hayan de cumplirlos no sea uno de sus miembros (art. 163 del RLGC).

\section{Perspectivas de Reforma}

Desde la publicación del DFL 5/2003 se han sucedido distintas iniciativas destinadas a modificar el texto de la LGC en uno u otro aspecto. De éstos el de mayor relevancia hasta ahora era el presentado el 9 de marzo de 2010 por moción del entonces senador Guillermo Vásquez Ubeda (Partido Radical Socialdemócrata), que perseguía introducir diversas modificaciones en dicha ley con el propósito de reforzar el carácter asociativo y la ausencia de ánimo de lucro que inspira a estas entidades (Boletín $\mathrm{N}^{\mathrm{O}}$ 6836-03).

Ese proyecto ha cedido su lugar a sentado a la Cámara de Diputados por el presidente Sebastián Piñera mediante el Mensaje No 270-359 (Boletín No 813226). Este último pretende modernizar la ley en una serie de aspectos de importancia y tiene los siguientes objetivos:

i) flexibilizar los requisitos necesarios para la constitución de las cooperativas y fortalecer su capacidad de gestión, preservando su carácter participativo (disminución del número de socios exigidos para formar una cooperativa, simplificación de las formalidades de convocatoria a junta general y del procedimiento de adopción de decisiones en cooperativas de menos de veinte socios);

ii) incentivar la eficiencia económica y la sustentabilidad finan-

ciera, otorgándoles estabilidad patrimonial mediante la participación de socios inversionistas (creación de la figura del socio inversor, sujeción al art. 28 de la LGB de los socios que superen el 10\% del capital de una cooperativa de ahorro y crédito, limitaciones al retiro de capital respecto de los socios que sobrepasen el 20\% del mismo, creación de una reserva legal obligatoria en cualquier cooperativa con un porcentaje no inferior al 20\% del remanente);

iii) actualizar el marco normativo de las cooperativas de ahorro y crédito, mejorando su competitividad en el mercado (aumento del capital mínimo exigido para su constitución de 1000 a $10.000 \mathrm{UF}$, facultad de constituir o tener participación en sociedades filiales para aquellas cooperativas de ahorro y crédito que tengan un patrimonio superior a 400.000 UF, supervisión y fiscalización de esas mismas cooperativas sólo por parte de la Superintendencia de Bancos e Instituciones Financieras);

iv) mejorar las facultades otorgadas al Departamento de Cooperativas para sancionar adecuadamente las conductas que afectan la sana administración cooperativa (tipificación de las infracciones a la ley, aumento del montante de las sanciones pecuniarias y otorgamiento a dicha repartición, en caso de infracciones reiteradas, de la fa- 
cultad de remover parcial o totalmente a los miembros del consejo de administración o al gerente general, o a ambos, y de convocar a junta general dentro de un plazo de treinta días para celebrar nuevas elecciones);

v) corregir errores de referencia, eliminar algunas normas sin aplicación y aclarar interpretaciones equivocadas producto de la aplicación de la LGC.

Pese a la extensión y profundidad con que son abordadas las materias en este proyecto, todavía queda pendiente el desafío de introducir criterios de flexibilidad y progresión que permitan que el marco normativo se adapte paulatinamente a la realidad concreta de cada ámbito o grupo de cooperativas en la línea sugerida por la recomendación No 193/2003 de la OIT y por el Plan para una década cooperativa preparado por la ACI. Asimismo, algunos aspectos sensibles para el sector cooperativo, como acaece con la función de fiscalización y supervisión del Departamento de Cooperativas, merecen una revisión más acuciosa orientada a la gradualidad, en la línea propuesta por el así llamado Estatuto de las empresas de menor tamaño (ley $\mathrm{N}^{\mathrm{o}}$ 20.416). En un plano más técnico, sería deseable que el nuevo texto de la LGC incluyese:

i) la mención de los principios y valores cooperativos como criterios hermenéuticos de la ley (art. $24 \mathrm{del} C C)$;

ii) una referencia a la interdicción de las discriminaciones basadas en el sexo y en la raza en consonancia con la orientación de la ley $\mathrm{N}^{\circ} 20.609$; iii) una regulación más minuciosa del procedimiento de ingreso de un socio a una cooperativa;

iv) una mayor claridad sobre los grupos cooperativos (materia sólo esbozada en el proyecto respecto de las cooperativas de ahorro y crédito);

v) la necesidad de hacer referencia al interés por la comunidad como parte del desenvolvimiento de la actividad cooperativa;

vi) la incorporación de mecanismos efectivos para promover la educación cooperativa.

\section{Conclusiones}

Para el Derecho chileno, en suma, la cooperativa es una persona jurídica de creación legal sin mayor promoción estatal dentro del engranaje económico del país, basada en el principio de la ayuda mutua y cuyo principal objetivo es mejorar las condiciones de vida de sus socios (arts. $1^{\circ}$ y $5^{\circ}$ de la LGC). De ahí que una de sus características fundamentales sea el que los socios tienen iguales derechos y obligaciones y un solo voto por persona, tanto en lo que se refiere a la elección de personas como en lo relativo a las proposiciones que se formulen (arts. $1^{\circ}$ y 22 de la LGC), dado que la maximización del capital no es un fin prioritario (art. 53 de la LGC). Llevado este principio al plano de la gestión, se traduce en la democracia participativa mediante la cual la cooperativa es administrada en la junta general de socios, considerada la autoridad suprema de la entidad (arts. 21 de la LGC y 26 del RLGC). Dicha junta se constituye por 
la reunión de los socios que figuren debidamente inscritos en el registro social y los acuerdos que adopte, con sujeción a las disposiciones legales, reglamentarias y estatutarias, son obligatorios para todos los miembros de la cooperativa. Por tratarse de una entidad sin fines de lucro, las cooperativas no producen utilidades (art. 53 de la LGC) y tienen un tratamiento tributario concordante con ese carácter y más favorable que el de otros agentes del mercado.

\section{ORientación bibliográfica}

1. El conjunto de fuentes de origen legal y administrativo que componen el Derecho Cooperativo chileno puede ser consultado y descargado desde la sección sobre "Normativa" del sitio web de la Departamento de Cooperativas (www.decoop.gob.cl/), que cuenta, además, con otras informaciones relevantes sobre este ámbito de la actividad económica. Existe ahí, por ejemplo, un manual de constitución, estructura básica y funcionamiento de cooperativas (12 pp), cuyo objetivo es entregar apoyo técnico a las personas interesadas en constituir o asesorar la constitución de una empresa productiva, que asocie a las personas de acuerdo con el modelo cooperativo, y en conocer a grandes rasgos su funcionamiento. Por su parte, las leyes y la jurisprudencia administrativa referida al régimen tributario de las cooperativas pueden ser revisadas en el sitio web del Servicio de Impuestos Internos (http://home.sii.cl/). En fin, el texto y estado de tramitación del proyecto de reforma en discusión en el Congreso
Nacional pueden ser consultados en los sitios web de la Cámara de Diputados (www.camara.cl/) y del Senado (www. senado.cl/), desde los que también es posible acceder a aquellos otros que aquí no han sido mencionados y que han perdido vigencia.

Son de obligada consulta, asimismo, los sitios de la ACI (http://ica. coop/), ACI-Américas (www.aciamericas.coop/), el European Research Insitute on Cooperative and Social Enterprises (www.euricse.eu/) y el Centro Internacional de Economía Social y Cooperativa (www.ciescoop.usach.cl/).

2. Pese a la larga presencia de las cooperativas en la actividad económica del país, y salvo algunos esfuerzos dignos de encomio, ellas no han concitado mayor atención de parte de la literatura científica, que entiende agotado el derecho de asociaciones en las modalidades de sociedades civiles y comerciales. Es necesario, pues, emprender con rigor un esfuerzo de reflexión y análisis sobre el "núcleo dogmático" del Derecho Cooperativo, que viene integrado por las instituciones, reglas y principios que otorgan especificidad a esta disciplina. Esa tarea es más sencilla de emprender en este ámbito que en otras parcelas, porque a su respecto existe una declaración sobre identidad cooperativa (1995) preparada por la ACI, que contiene una definición mínima de estas entidades, la enunciación de los valores que deben encarnar y la explicación de los siete principios que marcan las pautas mediante las cuales esos valores son puestos en práctica. Conviene igualmente consultar el Plan para una década cooperativa (2013) preparado por esta organización (en especial su 
capítulo IV dedicado a los marcos jurídicos), y los PECOL de próxima aparición [Gemma FAJARDO et al. (2012). "El nuevo grupo de estudio en Derecho cooperativo europeo y el proyecto 'Los principios del Derecho cooperativo europeo". Revista de Derecho de Sociedades No 39, Navarra, pp. 602-618]. Además, en el ámbito continental existe una ley marco para las cooperativas de América Latina, fuera de otros textos específicos aprobados por el MERCOSUR (por ejemplo, el Estatuto de Cooperativas Transfronterizas aprobado en 2009), bloque comercial del cual Chile sólo es Estado asociado. Una buena aproximación a las tendencias compradas es el Guidelines for Cooperative Legislation (Ginebra, OIT, $3^{\mathrm{a}}$ ed., 2013) preparado por Hagen HENRŸ, así como el International Handbook of Cooperative Law (Berlín/ Heidelberg, Springer, 2014) coordinado por Dante Cracogna, Antonio FICI y el propio Hagen HENRŸ, que recoge la situación legal de las cooperativas en treinta países y en los sistemas jurídicos trasnacionales.

Para una aproximación más general a la categoría del ánimo de lucro en las personas jurídicas, es útil tener en cuenta los trabajos de Juan Andrés VARAS BRAUn intitulados "Personas jurídicas sin fines lucrativos" [María Dora MARTINIC, Sebastián Ríos, Mauricio TAPIA (dirs.) (2005). Sesquicentenario del Código Civil de Andrés Bello. Santiago: LexisNexis, vol. I, pp. 463-476] y "Los fines en las personas jurídicas no lucrativas" [Carlos PIzARro Wilson (ed.) (2009). Estudios de Derecho civil IV. Santiago: LegalPublishing, pp. 73-85 = Hernán CORRAL TALCIANI et al. (coord.) (2011). Estudios de Derecho civil. Santiago: AbeledoPerrot-LegalPublis-
hing/Thomson-Reuters, vol. I, pp. 225253), así como su ponencia Bosquejo para una anatomía jurídica del lucro presentada en las XI Jornadas Nacionales de Derecho civil (Valdivia, 2013), que quedará incluida en sus actas.

3: En lo que atañe al detalle de la literatura existente, el tratado más completo y actual pertenece a Juan Pablo Román Rodríguez (2012). Cooperativas. Santiago: AbeledoPerrotLegalPublishing/ThomsonReuters, que corresponde a una reelaboración de su Introducción al derecho cooperativo chileno (1990). Santiago: Editorial Jurídica de Chile, redactado según la legislación anterior. Con menor pretensión y, por tanto, más breves, aunque igualmente útiles para acercarse a la disciplina cooperativa del DFL 5/2003, son la monografía de Gloria Molina Pinilla (2007). Cooperativas, entidades necesarias para el desarrollo del Estado de Derecho. Santiago: Librotecnia, y el documento de trabajo preparado por Ernesto Pérez ArocA, Mario Radrigán Rubio y Gabriela Martín Armengol (2003). Situación actual del cooperativismo en Chile. Santiago: Programa interdisciplinario de estudios asociativos Pro-Asocia/Universidad de Chile. Por su finalidad informativa, también es interesante la colaboración de Jorge Gompertz Pumarino, "La legislación cooperativa en Chile", incluida en el volumen colectivo al cuidado de Dante CRacogna (2009). La legislación cooperativa en los países andinos. San José de Costa Rica: ACI-Américas, pp. 35-84, así como las explicaciones de María Fernanda Vásquez Palma (2013). Sociedades Santiago: LegalPublishing/ThomsonReuters, pp. 177-215) 
o de Alberto Lyon Puelma (2003) Personas jurídicas. Santiago: Ediciones Universidad Católica de Chile. Con el mismo formato, pero referido a un aspecto particular de su régimen, es el trabajo de Jorge Gompertz Pumarino (2009). "La tributación cooperativa en Chile", en Dante Cracogna, La tributación cooperativa en los países andinos. San José de Costa Rica, Alianza Cooperativa Internacional para las Américas, pp. 31-67. Una explicación de la disciplina de la LGC a la luz de los principios contenidos en la Declaración de identidad cooperativa (1995) puede verse en el artículo de nuestra autoría "Los principios cooperativos en la legislación chilena". Revista Jurídica de Economía Social y Cooperativa. $\mathrm{N}^{\mathrm{o}} 19$, Valencia, 2009, pp. 201-291, donde se menciona un buen número de memorias de prueba, tesis de grado, materiales de trabajo y artículos de revista escritos sobre esta parcela en general y sobre los distintos tipos y aspectos de la actividad cooperativa en particular. De nuestra autoría son igualmente el capítulo "Cooperative Law in Chile". International Handbook of Cooperative Law antes citado, y que ofrece en inglés el contenido de la casi totalidad de este informe; y el artículo "El derecho cooperativo chileno: estado de la cuestión". Revista Jurídica Atena. No 5. Brasil, 2013.

Para formarse una idea de la anterior situación del Derecho Cooperativo chileno, son útiles las obras de Sergio Carvallo Hederra (1957). Manual de legislación cooperativa. Santiago: Editorial Jurídica de Chile y José Antonio RodríGUEZ VeLASCO (1968). Derecho cooperativo chileno. Santiago: Editorial Jurídica de
Chile, así como las recopilaciones de Sergio Fernández Faria (1971). Derecho cooperativo: legislación, jurisprudencia, prontuario. Santiago: Editorial Quilantal e Ismael EsPinOza VARGas (1974). Doctrina y legislación cooperativa. Santiago: Ediciones Nueva Universidad.

4. La historia del cooperativismo en Chile viene relatada en una temprana obra de Primo Bucchi Morelli (1929). El cooperativismo en Chile. Santiago, Imprenta Cisneros, y luego desarrollada con un mayor acervo de respaldo por Pablo Silva ManríQuez (1984). Historia del movimiento cooperativo. Santiago: CONFECOOP. Sobre épocas específicas se pueden revisar los textos preparados por SERCOTEC (1970). El movimiento cooperativo en Chile. Análisis del desarrollo en el período 1966-1969. Santiago, y CONFECOOP (1983). El movimiento cooperativo en Chile: análisis del período 1976-1982. Santiago.

Según ha quedado dicho, el período de mayor apogeo de las cooperativas se vivió durante la década de 1960, especialmente durante la segunda mitad de tal decenio, cubierta por el gobierno de inspiración democratacristiana conducido por el presidente Eduardo Frei Montalva (1964-1970). La importancia dada a estas entidades se debió al papel fundamental que aquéllas representaban dentro de la llamada "revolución en libertad", nombre del programa de gobierno del presidente Eduardo Frei M. con el que se perseguía emprender una reforma estructural del país desde los cuerpos intermedios y los principios del humanismo cristiano. El objetivo de ese programa económico y social era incentivar la "promoción popular", vale decir, crear organizaciones de base 
capaces de enfrentar los problemas de la sociedad civil en los mismos ámbitos donde la necesidad lo requiriese, de manera que a través de ellas se consiguiese mejorar las condiciones de vida de los sectores más desfavorecidos y potenciar el desarrollo integral del país por la senda del progreso. Fruto de estas ideas colectivistas es el perfeccionamiento de la legislación cooperativa, subsumida desde 1963 dentro del proceso de reforma agraria, y también la ley $\mathrm{N}^{\circ} 16.880$ sobre juntas de vecinos y demás organizaciones comunitarias (hoy aumentadas merced a la ley $\mathrm{N}^{\circ} 20.500$ sobre asociaciones). La función asignada a las cooperativas durante aquella época es abordada, con detalle, por José Polanco VAras (1985). El efecto del pensamiento y la obra del gobierno de don Eduardo Frei en el desarrollo del movimiento cooperativo chileno. Santiago: Instituto Chileno de Estudios Humanísticos. A comienzos de la década, empero, ya Carlos BURR Petri (1962). Las cooperativas. Una economía para la libertad. Santiago: Editorial del Pacífico, había llamado la atención sobre la directa conexión que existe entre las cooperativas y la promoción de un sistema económico centrado en las personas, de lo que da cuenta en su obra. De interés son también los trabajos publicados en esos años por el Centro de Estudios Cooperativos de la Pontificia Universidad Católica de Chile y el Departamento de Relaciones del Trabajo y Desarrollo Organizacional de la Universidad de Chile, varios de ellos citados en nuestro artículo sobre los principios cooperativos, como lo son hoy aquéllos producidos por el CIESCOOP, creado en 2009 por la Facultad de Administración y Economía de la Universidad de Santiago de Chile, cuya actividad en pro de este sector es feraz y digna de reconocimiento.

Algunas de las ideas que incidieron en el proceso de reformulación del Derecho Cooperativo que condujo a la dictación del DS 502/1978, del Ministerio de Economía, Fomento y Reconstrucción, pueden ser consultadas en el artículo de Rodolfo FigueROA Figueroa (1975). "Reforma de la Ley general de cooperativas". $R e^{-}$ vista Chilena de Derecho. ${ }^{\mathrm{os}} 1-2$, pp. 90-108. Una referencia a la disciplina surgida tras ese texto ofrecen Daniel Navas Vega (1987). "Las cooperativas en Chile". Perspectiva Económica. No 57 , Brasil, pp. 193-228, y Carlos Gilberto Villegas (1995). Tratado de las sociedades. Santiago: Editorial Jurídica de Chile, pp. 486-499, este último integrando su exposición en un panorama general del Derecho Societario vigente por aquel entonces (hoy modificado por distintas reformas legales relacionadas con el mercado de capitales y por la inclusión de nuevos tipos sociales y empresariales). La situación existente hacia fines del siglo $\mathrm{xx}$, cuando se discutía en el Congreso Nacional el proyecto de reforma sancionado finalmente a través de la ley $\mathrm{N}^{\circ} 19.832$, está descrito en el informe de Mario RADRIGÁn RUbio y Pedro del Campo Toledo (1998). El sector cooperativo chileno: tradición, experiencias y proyecciones. Santiago: CONFECOOP/CCA. Una mirada más amplia, comprensiva de todo aquel sector económico en el cual se incardinan las cooperativas, se ofrece en la colaboración de Mario RADRIGÁN Rubio y Cristina BARRÍA KNOPf, "Situa- 
ción y proyecciones de la economía social en Chile", en José María Pérez DE URALDE (coord.) (2006). La economía social en Iberoamérica. Un acercamiento a su realidad. Madrid: FUNDIBES, pp. 93-137.

5 . En fin, algunas ligeras sugerencias para la reforma de la legislación cooperativa desde una perspectiva técnica, escritas antes de que fuese presentado al Congreso el Mensaje $\mathrm{N}^{\circ}$. 270-359 (Boletín No 8132-26), se pueden encontrar en nuestro artículo "El marco jurídico cooperativo y sus perspectivas de reforma", que desarrolla la ponencia presentada en las Primeras Jornadas Chilenas de Derecho Comercial celebradas en la Universidad de Talca en 2010 [María Fernanda VÁsQuez Palma (dir.) (2011). Estudios de Derecho comercial. Santiago:
AbeledoPerrot/LegalPublishing, pp. 307-321]. Una versión preliminar de esa colaboración fue expuesta en el seminario "Marcos jurídicos para el sector cooperativo", organizado por CIESCOOP y realizado en la Universidad de Santiago de Chile el 21 de julio de 2010. Con todo, las ideas centrales de esa intervención y del texto que la desarrolla se hayan enunciadas al final del apartado XIII de este informe. Para un mayor desarrollo de ellas, se puede consultar nuestra ponencia sobre las perspectivas de reforma del derecho cooperativo chileno presentada en el V Congreso Continental de Derecho Cooperativo realizado con ocasión de la XVIII Conferencia Regional de ACI-Américas (Guarujá, 8-10 de octubre de 2013), y que se recogerá en sus actas. 